\title{
Brownfield Reuse Investment as a Tool for Limiting the Territorial Expansion of Settlements in Bulgaria
}

\author{
Anna Gospodinova ${ }^{1 *}$ \\ ${ }^{1}$ University of Economics - Varna, Department of Business, Investment and Real Estate, 77, Kniaz \\ Boris I Blvd., 9002 Varna, Bulgaria
}

\begin{abstract}
The goal set by the author of the study is to consider the good European practices in the remediation and reuse of Brownfields and on that basis to outline the possibilities for the use of these practices in Bulgaria in order to limit the territorial expansion of settlements (populated places) at the expense of non-urbanized areas. The specific character of the issue under study determines the following research methods as most suitable: the document analysis method; the comparison method; the methods of analysis and synthesis. There are laid down the possibilities for Brownfield reuse in Bulgaria. The reuse of the so-called brownfields combines the advantages of the environmental, the economic and the social development as it results in a more sustainable development of settlements, as well as in reduced reclamation and building up of green areas and non-urbanized land for the erection of new buildings and the development of infrastructure (social as well as technical).
\end{abstract}

The need to take a variety of measures in order to limit the adverse consequences of the uncontrollable territorial expansion of settlements (populated places) has been realized by many European countries. The good European practices in that respect are connected with the use and application of various tools, one of them being the regeneration and reuse of the so-called "brownfields" within towns and cities.

The territorial growth of some settlements in Bulgaria in recent years, on account of the acquisition of non-urbanized areas (mostly agricultural land) in their peripheral parts, is associated with a number of unfavorable consequences: spatial, economic, social and environmental.

According to data provided by the European Environment Agency [1] for the period 2000-2018, the size of the acquired non-urbanized areas in Bulgaria for the construction of different kinds of buildings and structures comes to 13,189 ha, of which 2,945 ha has been acquired for the development of new industrial and commercial sites. The big size of the acquired non-urbanized areas for industrial and commercial sites can be accounted for by the erection of large-scale industrial and commercial sites during the period 2000-2018 and the lack of sufficient free space in the construction boundaries of settlements, on the one hand, and - on the other - by the fact that the industrial and warehouse sites existing within

\footnotetext{
* Corresponding author: annagospodinova@ue-varna.bg
} 
the boundaries of settlements do not conform to contemporary standards, which is why investors turn towards the construction of new ones.

This creates the need to seek and identify possibilities for the regeneration and reuse of brownfields that are unusable within the construction boundaries of settlements. In most cases these abandoned and unusable sites (mainly industrial ones) are private property, but their disuse leads to a great number of negative economic, social, and environmental consequences.

The aim of the author of this article is to discuss some good European practices in the regeneration and reuse of brownfields and on that basis to outline the possibilities for the use of these practices in Bulgaria in order to limit the territorial expansion of settlements at the expense of non-urbanized areas.

According to the European Commission [2] "brownfields" refer to the abandoned unusable industrial grounds or disused former industrial or commercial sites, which may be polluted or be considered as such. They are found mainly in the urban areas of regions, in which there used to be highly-developed heavy industry, but nowadays this activity is discontinued. Their expedient use requires the coordinated intervention on the part of the owners, the local authorities and the citizens.

The abandoned industrial zones are defined by the Concerted Action on Brownfield and Economic Regeneration Network (CABERNET) also as [3]:

$\checkmark \quad$ affected in some way by previous operation and management of the territory and neighboring terrains;

$\checkmark \quad$ ownerless, abandoned and/or inadequately utilized and kept;

$\checkmark \quad$ zones which may have some real present or expected future issues, connected with pollution;

$\checkmark \quad$ located primarily in developed urbanized territories;

$\checkmark \quad$ requiring intervention in order to be utilized again.

$\checkmark$ According to Petríková et al. [4] abandoned industrial zones can be classified according to:

$\checkmark \quad$ their original use (industrial, institutional, military, agricultural, infrastructural, cultural, etc.);

$\checkmark \quad$ their size (small, large);

$\checkmark \quad$ the risks they constitute (level of pollution);

$\checkmark \quad$ their degree of unsuitability (for instance abandoned industrial zones, situated on roads providing access to human settlements, limiting the possibilities for local development).

The reuse of brownfields leads to a more sustainable development of urban territory and the suburbs, as well as to a decrease in the acquisition of green areas and non-urbanized land for the erection of new buildings and the development of infrastructure (social and technical). Brownfields can be used for the construction of modern office buildings, housing estates, mixed use developments, commercial sites, parks of public significance, etc. All this can lead to a renewed image of individual sections of the territory and attract population led by the motive for better career opportunities, through the provision of more jobs [5].

In certain EU countries (Great Britain, Czech Republic, France) by means of the cohesion policy there is provided funding aimed at promoting the construction of new sites on abandoned industrial areas, which is coordinated by special organizations [2].

In Great Britain, the Agency for Housing and Communities provides financing for the construction of homes for social housing on abandoned areas.

The government of Great Britain undertakes to maximize the number of new homes built on brownfields. Brownfields are included in the national planning policy framework. All local planning authorities are required to publish a Brownfield Land Register [6]. 
The Brownfield Land Register provides up-to-date information on sites, which local authorities consider suitable for residential construction, taking into account the criteria set in Regulation 4 of the Regulations on Urban and Rural Planning (Brownfield Land Register) [7]. The registers consist of two parts. The first part contains all brownfields suitable for residential construction, whereas the second part contains those for which there has been obtained a permit. The registers are published locally and the data in them are public.

In the Czech Republic the reuse of abandoned industrial zones is connected with control over the change in land use and not so much with the application of practical measures. Besides collecting data about the abandoned industrial areas, of great importance is also the analysis of these data from the point of view of the potential for development of brownfields.

The Business and Investment Development Agency in the Czech Republic offers the following services with respect to brownfields [8]:

$\checkmark \quad$ mapping and identification of sites that are suitable for carrying out projects in different parts of the Czech Republic by means of the created database of brownfields. The national database contains information about the number, characteristics and development of brownfields in the Czech Republic and serves both for obtaining information on the part of investors, and for statistical purposes;

$\checkmark$ provision of information and administration of programs aimed at aiding the regeneration of brownfields through financing from the state budget and from European Funds;

$\checkmark$ organization of views/surveys of selected sites;

$\checkmark \quad$ organization of workshops and conferences connected with the use of brownfields.

In France there is in operation a network of more than 20 agencies for the development of public lands, which - along with carrying out other activities - also build up social homes on abandoned brownfield land.

In the region Nord-Pas-de-Calais, for instance, the establishment of such an Agency was justified by the social and economic challenges, linked with the industrial restructuring during the 1970s. In the 1980s, the area of brownfields in this region reached approximately 10,000 hectares, or $50 \%$ of all brownfields in France. The goal of the Agency is the reuse of the legacy industrial sites for new activities, and during the period between 1989 and 2006 the agency took part in the revival of 4,752 hectares of brownfields [9].

Created in 1990, the German Privatization Agency Treuhand aimed at privatizing about 8,500 East German state-owned enterprises. A large part of the privatized sites was connected with the reuse of the brownfields. In order to raise the investment interest in those sites the Agency offered various incentives to investors. Some of these incentives were connected with the cost of surveying and regenerating the brownfields, which was included in the contracts signed with investors, whereby $60 \%$ of that cost was borne by the Agency. In certain cases, the Agency covered up to $90 \%$ of the cost connected with the environment. In 1994 the Agency transferred its activities to three other agencies, one of which was Treuhand Liegenschaftsgesellschaft $\mathrm{mbH}$, engaged in the management of the remaining state-owned urban and industrial real property [9].

In Austria the state does not provide any opportunities for financing projects, connected with the redevelopment of brownfields. Such opportunities may be sought indirectly from other funds for financing the following: housing, business development and protection of historical monuments.

In Vienna, for instance, financial opportunities for the redevelopment of brownfields may be used by way of funds which are not specifically connected with financing the redevelopment of brownfields, but which may be used for that purpose as well: 
$\checkmark \quad$ Vienna Economic Development Fund - for industrial sites;

$\checkmark \quad$ Fund for Residential Construction and Urban Renewal - for housing sites, including the construction of social homes, as well as for the preparation, development and implementation of measures aimed at the renewal of towns and cities, especially for consulting, coordination, and control over the subsidized improvement of housing [10].

The solving of the issues of the abandoned industrial zones in Romania is connected with conducting a number of surveys and constantly updating various lists, as well as with amendments and supplements to the legislation in the field of territorial development at the regional and urban level, concerned with the spatial planning and drafting of urban and territorial development plans, so as to enable the assessment, analysis and inclusion of the abandoned industrial zones in the short-term, medium-term and long-term plan [11].

In Bulgaria the design, development and management of industrial, economic, and free zones is carried out by National Company Industrial Zones EAD (a company with the Ministry of Economy), which creates the conditions for attracting investors, including foreign ones. The company offers industrial sites/grounds as well as production and storage rooms. It manages 11 projects throughout the country with a total area in excess of 7.4 million square meters. Seven active projects are in the cities and towns of Sofia, Burgas, Vidin, Ruse, Svilengrad, Stara Zagora and Varna. Under development are five projects: in Kardzhali, Stara Zagora, Karlovo, Telish and Suvorovo. As a result of the cooperation of the National Company Industrial Zones (NCIZ) with the local authorities (based on concluded memoranda for the formation and development of new industrial zones), the local authorities identify sites/grounds suitable for industrial purposes, which the NCIZ then offers to potential investors [12]. The information on the identified grounds, however, is not public and is provided only upon the showing of interest on the part of would-be investors and in connection with the realization of ad hoc projects with the local authority for the development of the site/grounds with the needed infrastructure for the project of a particular investor. In this regard it would be more appropriate to broaden the cooperation between the NCIZ and the local authorities towards providing more publicity to the information (not only about areas that are free from construction, but also about unusable brownfields) in order to attract a greater number of potential investors.

According to Petríková et al. [4] the process of reconstruction and renewal of abandoned industrial zones in Bulgaria passes through several steps. The first step is an onsite survey of the current state of the site, a description of its previous use and an assessment of its potential future use. When gathering the necessary information of great importance is establishing who the owner or owners of the property are. The owners may be the state, the municipality, and also private individuals. The fragmentation of the ownership of industrial sites among multiple owners, as a result of the processes of restitution and privatization after 1989, creates certain difficulties in the process of renewal of abandoned industrial zones. The next step is the drawing up of a plan for carrying out specific actions. The respective site can be reconstructed or demolished, and the land can be reused. The reuse of abandoned industrial sites may be accomplished through private initiative (by owners or investors) or through the participation of municipalities in national, regional, or European initiatives and programs for renewal and development. One example in this respect is the municipality of Pernik. The municipality is a partner in the realized European project "Revitalization of traditional industrial zones in South-East Europe ReTinA" under The South-East Europe Transnational Cooperation Program for the period 2007-2013, funded by the European Regional Development Fund. The project is connected with pooling the efforts of the municipality of Pernik and the small and medium-sized enterprises in operation that have emerged after the privatization of the former steel works Stomana (Stomana Industry SA), for the construction of a large industrial business park in Pernik in order to increase the attractiveness of the zone and attract investors to it and in the 
municipality of Pernik as a whole.

The revitalization and reuse of abandoned industrial zones in Bulgaria is included in the Integrated Plans for Urban Reconstruction and Development for the period 2014-2020 of the individual municipalities and the Plans for Integrated Development of Municipalities for the period 2021-2027. These plans outline the main goals and stages, as well as the ways to carry out predetermined procedures, the required documentation, and the conditions for evaluation of their implementation, and also the expected results and the potential favorable impacts of the renewal of abandoned industrial sites.

It would be advisable that the abandoned industrial zones be originally specified in the master spatial development plans of municipalities, since these documents outline the vision for the long-term development of the individual settlements (populated places) in a particular municipality for a period of 15-20 years, whereas the plans for the integrated development of municipalities are effective for a period of 7 years and are perceived as strategic and programming documents, determining the medium-term goals and development priorities of municipalities by delineating specific parameters for the development and the resource security of the execution.

The reuse of each individual site, characterized as a brownfield, is determined by its economic efficiency. The economic efficiency is affected by a number of factors, which may change considerably over time, among which are the following [13]: cost of the revitalization and reuse of the site; return on the investment made; type of financing and the financial risk associated with it; national and local taxes and charges; arrangements between the landowner and/or the municipality and the developer (investor). To these factors there may also be added the socioeconomic development of the country and the region in which the respective site is located, as well as the development of the real estate market.

In the making of decisions concerning the reuse of brownfields there could be used the conceptual model for characterization of the various types of brownfield in terms of their economic efficiency, known as the A-B-C model, developed and used by CABERNET.

The use of this model can promote the development of abandoned and unusable sites (predominantly industrial ones) in the big towns and cities of the country and thus limit the expansion of settlements at the expense of non-urbanized territories.

The different kinds of projects for reuse of the so-called "brownfields" according to their economic importance are presented in Fig. 1.

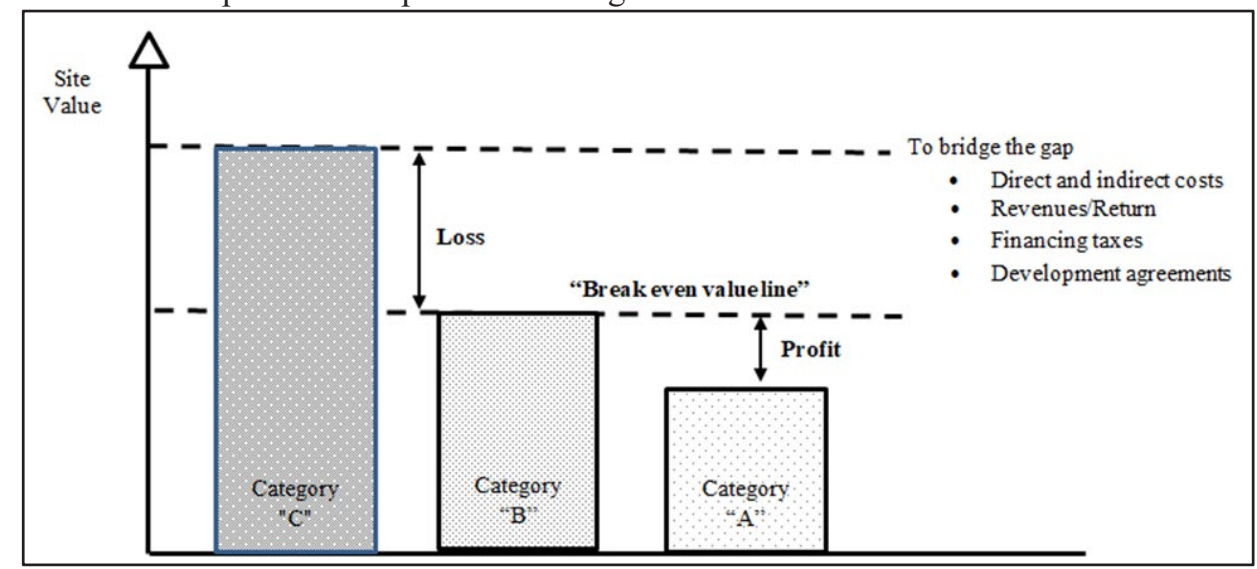

Fig. 1. Economic components of the A-B-C model [14]

The conceptual model A-B-C of CABERNET identifies three types of sites depending on their economic efficiency (for example in terms of the cost of revitalization and reuse of the 
site, the cost of land, etc.) [14]:

- abandoned and unusable sites category "A" - these are sites, which are economically efficient, and their revitalization and reuse is carried out by private investors;

- abandoned and unusable sites category "B" - these sites are borderline cases of costeffectiveness (economic efficiency), which is why their revitalization and reuse is carried out following the principle of public-private partnership;

- abandoned and unusable sites category " $\mathrm{C}$ " - with these sites the revitalization and reuse are not economically efficient, therefore the investments in those should be made by the public authorities. In order to promote the development of this particular category of sites there is needed public financing, or specific legislative tools providing certain incentives.

The model presented above outlines the possibilities for financing the reuse of brownfields. Through the identification of the individual categories of sites, the public authorities, the owners of these sites, as well as the potential investors can examine the prospective benefits from a future reuse of the respective site, as well as undertake the appropriate strategies aimed at restoring its use.

With regard to this it would be expedient to create a database containing information about the abandoned (unusable) sites in Bulgaria, in terms of their location, area, form of ownership, year of construction, manner of previous use, manner of permanent use and of permanent use of the land on which they have been built, functional purpose, information about the territory on which they are located (characteristics, issues, development potential, socioeconomic information, possible or already detected contamination, estimates of the extent of contamination (kind of contamination) and estimated remediation costs), possibilities for financing their reuse through various national and European programs and projects, etc. The information about these sites could be part of the unified public register on spatial planning, which is to be created on the Internet page of the Ministry of Regional Development and Public Works in compliance with the provisions laid down in the Spatial Planning Act. Another option is to create an independent register, which would be published on the Internet page of the National Company Industrial Zones EAD.

In order to promote the development and reuse of brownfields which fall into category "B" of the A-B-C model of CABERNET (i.e., those which are on the breakeven line of profitability), it is necessary to create tax incentives for the owners of these properties, including the financing of part of the activities on their revitalization by the public authorities. The redevelopment of brownfields will also lead to an increase in the value of the surrounding pieces of real property, and hence the attractiveness of the territory/area as a whole. As a result of this it is possible to have an increase in tax revenue on account of the increase in the tax on the properties for the respective region. From that viewpoint the local authorities should aid the financing of the reuse of such properties, which will otherwise continue to be deserted, and on account of that there will be acquired new territories for the realization of large-scale investment projects.

Another incentive to the owners of these properties or to would-be investors can be the deduction of part of the costs, associated with the revitalization and reuse of the brownfields, from the tax on the property.

In conclusion it may be noted that the reuse of the so-called "brownfields" combines the advantages to the environmental, economic, and social development of a particular area, and in this regard the study and adaptation of the European expertise with respect to the possibilities for their revitalization and reuse is a suitable basis for limiting the processes of territorial expansion of settlements (populated places) in Bulgaria.

\section{References}


1. European Environment Agency, Land cover and change statistics 2000-2018, https://www.eea.europa.eu/data-and-maps/dashboards/land-cover-and-change-statistics [Accessed: 28 May 2021]

2. European Commission, Guidelines on best practice to limit, mitigate or compensate soil sealing, Commission Staff Working Document, 40 (2012)

3. CABERNET, http://www.cabernet.org.uk/ [Accessed: 1 June 2021]

4. D. Petríková, et al., Brownfields - Handbook BROWNTRANS, 23-69 (2012)

5. United States Environmental Protection Agency, Overview of EPA's Brownfields Program, https://www.epa.gov/brownfields/overview-epas-brownfields-program [Accessed: 3 May 2021]

6. Old Oak and Park Royal Development Corporation, Brownfield Land Register, https://www.london.gov.uk/about-us/organisations-we-work/old-oak-and-park-royaldevelopment-corporation-opdc/get-involved-o--6 [Accessed: 15 May 2021]

7. UK Parliament, The Town and Country Planning (Brownfield Land Register) Regulations, (2017), https://www.legislation.gov.uk/uksi/2017/403/regulation/4/made [Accessed: 15 May 2021]

8. Business and Investment Development Agency, Brownfields, https://www.czechinvest.org/en/Our-services/Real-estate-offer/Brownfields [Accessed: 1 May 2021]

9. World Bank, The Management of Brownfields Redevelopment, 11-12 (2010), https://documents1.worldbank.org/curated/en/754171468295822120/pdf/550090WP0P 118011PUBLIC10brownfields.pdf [Accessed: 2 May 2021]

10. G. Siebielec, et al., Brownfield Redevelopment as an Alternative to Greenfield Consumption in Urban Development in Central Europe, Deliverable Report No: 6.1.3, European Union European Regional Development Fund and Urban SMS Soil Management Strategy, Stuttgart, 17 (2012)

11. European Court of Auditors, Have EU Structural Measures successfully supported the regeneration of industrial and military brownfield sites?, 55 (2012), https:/op.europa.eu/en/publication-detail/-/publication/6e4855e6-5921-410d-829e7ba60338427a [Accessed: 13 May 2021]

12. Official website of the National Company Industrial Zones, URL: http://nciz.bg/

13. U. Ferber, P. Nathanail, J. Jackson, M. Gorski, L. Drobiec, D. Petríková, Brownfields handbook: Cross-disciplinary educational tool focused on the issue of brownfields regeneration, Lifelong educational project on brownfields. Leonardo da Vinci pilot project CZ /04/B/F/PP-168014, The European Commision, 9-21 (2006)

14. CABERNET, Sustainable Brownfield Regeneration: CABERNET Network Report, 44 (2006), https://www.yumpu.com/en/document/view/38906007/sustainable-brownfieldregeneration-cabernet-network-report [Accessed: 13 May 2021] 